\title{
FOME, POBREZA E O PROGRAMA BOLSA FAMÍLIA NO NORTE PIONEIRO DO ESTADO DO PARANÁ
}

\author{
Pedro Henrique Carnevalli Fernandes ${ }^{1}$ \\ Vanessa Maria Ludka ${ }^{2}$
}

\section{Resumo}

A discussão sobre a fome e a pobreza na Geografia brasileira não é recente. Apesar disso, ainda é possível constatar a presença delas em todas as regiões do território brasileiro. Por isso, as políticas públicas de transferência de renda precisam se manter - e até serem ampliadas em algumas localidades - de modo a proporcionar uma condição humana às pessoas. Uma dessas políticas é o Programa Bolsa Família, do Governo Federal. Nesse sentido, esta pesquisa tem como objetivo principal refletir acerca da fome, da pobreza e do alcance do Programa Bolsa Família no Norte Pioneiro do Estado do Paraná. Além disso, espera-se avançar teoricamente acerca do conceito de fome e demonstrar a presença do Programa Bolsa Família na região, possibilitando comparar os dados de pobreza com os de beneficiários. Os procedimentos metodológicos foram: levantamento dos referenciais teóricos acerca da fome publicados por Josué de Castro; levantamento de dados de pobreza e de beneficiários do Programa Bolsa Família na região Norte Pioneiro do Paraná; e, por fim, elaboração de produções cartográficas. $\mathrm{O}$ direito à alimentação, nos debates de Marília Leão, é o direito a ter acesso regular e, permanente e livre, diretamente ou por meio de compras monetárias, a um alimento adequado e suficiente, porém, pode ser constatado que inúmeras pessoas no Norte Pioneiro do Paraná têm esse direito violado, convivendo com a fome e com a pobreza.

Palavras chave: Geografia da Fome. Taxa de Pobreza. Bolsa Família. Norte Pioneiro do Paraná.

\section{HUNGER, POVERTY AND THE "BOLSA FAMÍLIA" PROGRAM IN THE PIONEER NORTHERN OF THE STATE OF PARANÁ}

\begin{abstract}
The discussion about hunger and poverty in Brazilian Geography is not recent. Despite this, it is still possible to verify their presence in all regions of the Brazilian territory. For this reason, public income transfer policies need to remain - and even expanded in some locations - in order to provid a human condition to people. One of these policies is the Federal Government's "Bolsa Família" Program. In this sense, this paper has as main objective to reflect on hunger, poverty and the scope of the "Bolsa Família" Program in the Pioneer Northern of the State of Paraná. In addition, it hoped to theoretically advance about the concept of hunger and demonstrate the presence of the "Bolsa Família" Program in the

\footnotetext{
${ }^{1}$ Professor adjunto da Universidade Estadual do Norte do Paraná (UENP). Doutor em Geografia pela Universidade Estadual de Maringá (UEM). E-mail: pedrofernandes@uenp.edu.br.

2 Professora adjunta da Universidade Estadual do Norte do Paraná (UENP). Doutora em Geografia pela Universidade Federal do Paraná. E-mail: vanessaludka@uenp.edu.br.
} 
region, making it possible to compare poverty data with those of beneficiaries. The methodological procedures were survey of theoretical references about hunger published by Josué de Castro; survey of poverty data and beneficiaries of the "Bolsa Família" Program in the Pioneer Northern region of Paraná; and, finally, elaboration of cartographic productions and the final writing. The right to food, in the debates of Marília Leão, is the right to have regular and permanent and free access, directly or through monetary purchases, to adequate and sufficient food, however, it can be seen that countless people in Pioneer Northern of Paraná have this right violated, living with hunger and poverty.

Keywords: Geography of Hunger. Poverty rate. Bolsa Família. Pioneer Northern of Paraná.

\section{HAMBRE, POBREZA Y PROGRAMA "BOLSA FAMILIA" EN EL PIONERO NORTE DEL ESTADO DE PARANÁ}

\section{Resumen}

La discusión sobre el hambre y la pobreza en la Geografía brasileña no es reciente. A pesar de esto, es posible verificar su presencia en todas las regiones del territorio brasileño. Por esta razón, las políticas públicas de transferencia de ingresos deben mantenerse, e incluso expandirse en algunos lugares, con el fin de proporcionar una condición humana a las personas. Una de estas políticas es el Programa "Bolsa Família" del Gobierno Federal. En este sentido, esta investigación tiene como objetivo principal reflexionar sobre el hambre, la pobreza y el alcance del Programa "Bolsa Família" en el Pionero Norte del Estado de Paraná. Además, se espera avanzar teóricamente sobre el concepto de hambre y demostrar la presencia del Programa "Bolsa Família" en la región, lo que permite comparar los datos de pobreza con los de los beneficiarios. Los procedimientos metodológicos fueron: estudio de referencias teóricas sobre el hambre publicado por Josué de Castro; encuesta de datos de pobreza y beneficiarios del Programa "Bolsa Familia" en la región del norte de Pionero en Paraná; y, finalmente, la elaboración de producciones cartográficas y la redacción final. El derecho a la alimentación, en los debates de Marília Leão, es el derecho a tener acceso regular y permanente y gratuito, directamente o mediante compras monetarias, a una alimentación adecuada y suficiente, sin embargo, se puede ver que innumerables personas en el norte de Pionero do Paraná han violado este derecho, viviendo con hambre y pobreza.

Palabras clave: Geografía del Hambre. Tasa de pobreza. Bolsa Família. Pionero del Norte de Paraná.

\section{INTRODUÇÃO}

A discussão do problema da fome na Geografia brasileira não é recente, pois desde meados do século XX esse tema foi discutido por Josué de Castro, um dos maiores estudiosos sobre o tema e que se tornou referência dessa discussão. Para isso, este artigo contempla as obras “A alimentação brasileira à luz da Geografia Humana" (1937), "Geografia da Fome” 
(2001), “Geopolítica da Fome” (1961), “O livro negro da fome” (1966) e “O problema da alimentação no Brasil” (1939).

A fome é um fenômeno essencialmente geográfico, pois, como pontua Castro (1937; 2001), ela é universal e nenhum continente escapa da sua ação nefasta, sendo que a Geografia pode orientar o espírito humano na análise do problema como um fenômeno ligado à ação do homem, ao solo, ao clima, à vegetação e ao horizonte de trabalho em conexões. Além disso, a fome tem sido desde sempre a razão de mudanças sociais, progressos técnicos, revoluções e contrarrevoluções, ou seja, nada teve mais influência na história da humanidade, nenhuma doença, nenhuma guerra, nada é tão letal, e ao mesmo tão evitável, como a fome (CAPARRÓS, 2016).

O direito à alimentação é o direito a ter acesso regular e, permanente e livre, diretamente ou por meio de compras monetárias, a um alimento qualitativo e quantitativamente adequado e suficiente, porém, dentre todos os direitos humanos, é seguramente o mais constante e maciçamente violado (LEÃO, 2013). Nesse sentido, "O Direito humano à alimentação adequada e o Sistema Nacional de Segurança Alimentar e Nutricional" (2013), de Marília Leão traz inúmeras reflexões e contribuições quanto ao tema.

A exclusão social, a pobreza e a fome são fenômenos sociais mundiais tão antigos quanto o ideal pela busca de uma sociedade equitativa. Impressiona profundamente a sua face mais cruel: a fome, como impossibilidade dos cidadãos de acessar a direitos sociais básicos, em virtude do processo de concentração de renda e acesso desigual às oportunidades na sociedade brasileira. Tratar o problema da fome como questão nacional e não como fatalidade individual é responsabilidade de toda sociedade e dos governos, nas suas esferas federal, estadual e municipal.

O objetivo principal deste artigo é refletir acerca da fome, da pobreza e do alcance do Programa Bolsa Família na região Norte Pioneiro do Estado do Paraná. Para isso, tem-se como objetivos específicos: avançar teoricamente no debate sobre a fome a partir do clássico Josué de Castro; compreender os dados de pobreza no Norte Pioneiro do Estado do Paraná e entender os dados de beneficiados do Programa Bolsa Família no Norte Pioneiro do Estado do Paraná.

Os procedimentos metodológicos foram: levantamento de referenciais teóricos produzidos por Josué de Castro $(1937 ; 1939 ; 1961 ; 1966 ; 2001)$ acerca da fome; levantamento de dados de pobreza e de beneficiados do Programa Bolsa Família nos municípios do Norte Pioneiro; e, por fim, elaboração de produções cartográficas e da redação 
final. O Norte Pioneiro do Estado do Paraná, recorte espacial da pesquisa, compreende, segundo o IBGE (2008; 2010), 46 municípios, 7,5\% do território paranaense e 5\% da população do Paraná.

O levantamento da taxa de pobreza ocorreu por meio do Instituto Paranaense de Desenvolvimento Econômico e Social (IPARDES, 2019), com base nos dados do Instituto Brasileiro de Geografia e Estatística (IBGE) para o Censo Demográfico de 2010. Segundo o Ipardes (2019), a taxa de pobreza se refere à proporção dos indivíduos com renda domiciliar per capita igual ou inferior a $\mathrm{R} \$ 140,00$ mensais, em reais de agosto de 2010 , sendo que o universo de indivíduos é limitado àqueles que vivem em domicílios particulares permanentes.

O levantamento de beneficiados do Programa Bolsa Família ocorreu por meio de Brasil (2019), referente à Secretaria Especial do Desenvolvimento Social do Governo Federal, com base em dados referentes à setembro de 2019. Segundo Brasil (2019), o Bolsa Família é um programa de transferência direta de renda que atende famílias em situação de extrema pobreza e pobreza, identificadas no Cadastro Único para Programas Sociais do Governo Federal. Atualmente, são elegíveis ao programa, as famílias que tenham cadastros atualizados nos últimos 24 meses e renda mensal por pessoa de até $\mathrm{R} \$ 89,00$ ou renda mensal por pessoa de $\mathrm{R} \$ 89,01$ a $\mathrm{R} \$ 178,00$, desde que possuam crianças ou adolescentes de 0 a 17 anos em sua composição (BRASIL, 2019).

Nesse sentido, o desenvolvimento do artigo está estruturado da seguinte forma, além da introdução e das considerações finais: a segunda parte apresenta a base teórica da fome a partir de Josué de Castro; a terceira parte aborda os resultados acerca dos dados de pobreza na região Norte Pioneiro do Estado do Paraná; e, finalmente, a quarta destaca os resultados dos dados beneficiados do Programa Bolsa Família na região Norte Pioneiro do Estado do Paraná.

\section{DEBATENDO A FOME NA PERSPECTIVA GEOGRÁFICA DE JOSUÉ DE CASTRO}

No mundo, há aproximadamente 870 milhões de pessoas que sofrem de subnutrição, segundo a Organização das Nações Unidas para a Alimentação e a Agricultura (FAO, 2018). A média de subnutridos representa $12,5 \%$ da população mundial. Mas, os percentuais aumentam para $23,2 \%$ nos países em desenvolvimento e caem para $14,9 \%$ nas nações desenvolvidas.

No Brasil, segundo a FAO (2018), o combate à fome no Brasil se estagnou. A entidade estima que em 2017 havia "menos de 5,2 milhões" de brasileiros passando fome, 
uma mudança marginal em comparação aos números que vinham sendo apresentados nos últimos anos. Em 2014, essa taxa era de "menos de 5,1 milhões". Dois anos antes, o volume era de 5 milhões. O ponto mais baixo foi atingido em 2010, quando "menos de 4,9 milhões" de brasileiros eram considerados famintos. Em 2019, estima-se que 13 milhões de brasileiros passem fome diariamente.

Nesse sentido, viu-se a necessidade de discutir a fome buscando a sua compreensão e o rompimento com o silêncio em torno do assunto e com os paradigmas que a explicavam como um fenômeno natural, pois é necessário apontar esse espectro como consequência das estruturas sociais defeituosas historicamente herdadas e, nesse sentido, instituir uma nova forma de analisar esses fenômenos. É importante enfatizar que este artigo transita pelas principais obras de Josué de Castro. No entanto, há o reconhecimento e a relevância de outros autores que também têm debatido a problemática da fome na Geografia, como Jean Ziegler, em "Destruição em Massa: Geopolítica da fome" (2013), Martín Caparrós, em "A fome" (2016), Melhem Adas, em “A fome: crise ou escândalo?” (1988), Ricardo Abramovay, em "O que é a fome" (1985). Além disso, desde 1945 que a FAO lidera os esforços internacionais de erradicação da fome e da insegurança alimentar.

No livro "O Problema da alimentação no Brasil" (3 edição), Castro (1939) relata que quando começou seus estudos, em 1930, a sua maior surpresa foi a de não encontrar quase nada, em língua portuguesa, acerca do problema da alimentação. A surpresa fora ainda mais desconcertante porque nos Estados Unidos os interesses pelo assunto era enorme e com publicações diárias. Assim, para Castro (1939), o fator alimentar, agindo sobre o homem e a sociedade brasileira, em conexão com outros fatores, foi durante muito tempo inteiramente ignorado, sendo que ninguém apontava a alimentação como causa capaz de influir nas diretrizes da organização social. Então, é a partir da década de 1930 que o problema alimentar começou a despertar algum interesse por parte das forças dirigentes do Brasil (CASTRO, 1939).

Já nos seus primeiros estudos, Castro $(1939$, p. 80), pontuou que "sendo o Brasil um país pobre, mantém seus habitantes num baixo estândar de vida, resultando daí que os salários não permitem nenhuma liberdade na aquisição de alimentos, principalmente do grupo das albuminas - carne, peixes, leite, ovos, etc., de custo mais elevado" e, quase três décadas depois, Castro (1961) chamou a atenção para a "fome oculta', a qual constitui hoje uma forma típica da fome de fabricação humana. 
Para o autor, várias foram as razões que determinaram o fato de que a fome oculta constitua uma calamidade dos grupos humanos mais civilizados. A primeira delas é a monotonia alimentar, imposta pela civilização e que representa o hábito do homem civilizado de nutrir-se à base de um número restrito de substâncias alimentares. Se comparar a alimentação dos grupos primitivos com a do homem civilizado, a primeira diferença essencial é que enquanto o primitivo dispunha de um número infinito de plantas nativas e animais que serviam de alimentos, o civilizado restringe esses recursos a um pequeno número (CASTRO, 1961).

Com a restrição do número de substâncias alimentares em sua dieta, o civilizado aumentou as probabilidades de que se constituam deficiências habituais de alguns dos princípios nutritivos essenciais, que a grande variedade alimentar seria capaz de corrigir. Com a alimentação variada do dia a dia, as deficiências específicas de um dia são compensadas no dia seguinte, enquanto que, com a alimentação monotonamente igual, as deficiências se consolidam e se agravam através dos tempos (CASTRO, 1961).

Outro fator de agravamento das carências específicas entre os grupos mais civilizados é o uso generalizado dos alimentos concentrados, purificados ou refinados. Uma das formas mais graves e generalizadas de carências - de fome específica - é a deficiência de proteínas. Constituem as proteínas os elementos essenciais da estrutura do protoplasma vivo, representando, pois, o substrato da própria vida. São substâncias químicas de composição muito complexa que os vegetais elaboram abandonando o azoto do solo, do carbono do ar e de outros elementos do meio ambiente, combinando-os sob a ação energética da luz solar. Só as plantas são capazes disso porque os animais, embora dotados de vida muito mais intensa, não possuem o segredo da criação da matéria viva à custa dos elementos inorgânicos. Por isso mesmo, o homem e os outros animais dependem sempre do mundo vegetal para a sua existência. (CASTRO, 1961).

Outro grupo de fomes específicas de larga distribuição humana é o das deficiências alimentares em determinados princípios minerais. A importância dos sais minerais na alimentação é tão relevante quanto à do total de energia ou a do mínimo de proteína exigido pelo funcionamento vital. Realmente, uma dieta completa sob os vários aspectos da alimentação, não contendo, porém, certa dose de cálcio ou de ferro, por exemplo, acarreta perturbações graves ao ser vivo que a consome. A importância dos sais minerais na economia decorre da infinidade de funções que estas substâncias têm a desempenhar no mecanismo 
vital e do fato de não serem as mesmas mutuamente substituíveis nessas funções (CASTRO, 1961, p. 103).

Percebe-se que a persistência desse fenômeno não está ligada à escassez ou dificuldade física de acesso aos alimentos, mas, ao baixo poder aquisitivo de boa parcela da população que, por conta disso, não proporciona renda suficiente para que essas pessoas possam alimentar-se de forma adequada diariamente: “(...) já é passado o tempo em que as pessoas pobres podiam se conformar segundo a frase das Escrituras: 'Aos pobres é reservado é reservado o reino dos céus'. Agora devemos pensar que aos pobres deve também ser reservado o reino da Terra" (CASTRO, 2001, p. 125).

Assim, a Geografia da Fome, construída principalmente pelos estudos de Josué de Castro, destacar-se pelo rompimento com o silêncio em torno da fome e com os paradigmas que a explicavam como um fenômeno natural. Assim, Castro questiona (1961): será a calamidade da fome um fenômeno natural, inerente à própria vida, uma contingência irremovível como a morte? Ou será a fome uma praga social? "A fome não é um fenômeno natural, e sim, um produto artificial de conjunturas econômicas defeituosas: um produto de criação humana e, portanto, capaz de ser eliminado pela vontade criadora do homem" (CASTRO, 1966, p. 23). Além disso, [...] “a fome coletiva é um fenômeno de categoria social, provocado via de regra, pelo aproveitamento inadequado das possibilidades e recursos naturais ou pela má distribuição dos bens de consumo obtidos" (CASTRO, 1961, p. 371).

Portanto, não se pode admitir que a fome é um fenômeno natural, uma vez que ela é condicionada por fatores de natureza econômica. A fome constitui uma das expressões da problemática social, em decorrência do processo histórico de concentração de renda. A fome não é decorrência da baixa produção de alimentos, mas da falta de recursos da população, que não possui renda suficiente para adquiri-los.

O primeiro dos nossos objetivos é demonstrar que a fome, apesar de constituir fenômeno universal, não traduz uma imposição da natureza. Estudando a fome em diferentes regiões da Terra, poremos em evidência o fato de que, via de regra, não são as condições naturais que conduzem os grupos humanos à situação de fome, e sim certos fatores culturais, produto de erros e defeitos graves das organizações sociais em jogo. A fome determinada pela inclemência da natureza constitui um acidente excepcional, enquanto que a fome como praga feita pelo homem constitui uma condição habitual nas mais diferentes regiões da Terra: toda terra ocupada pelo homem tem sido por ele transformada em terra da fome (CASTRO, 1961 p. 79).

Para Castro (2001 p. 34), o único método, para estudar o fenômeno da fome em sua realidade total, permite compreender o problema em sua realidade total, sem arrebentar-lhe as 
raízes que o ligam subterraneamente a numerosas outras manifestações econômicas e sociais da vida dos povos. Não o método descritivo da antiga Geografia, mas o método interpretativo da moderna Ciência Geográfica, que se corporificou dentro dos pensamentos fecundos de Ritter, Humboldt, Jean Brunhes, Vidal de La Blanche, Griffih Taylor e tantos outros.

\footnotetext{
Só a geografia, que considera a terra como um todo, e que ensina a saber ver os fenômenos que passam em sua superfície, a observá-los, agrupá-los e classificá-los, tendo em vista a localização, extensão, coordenação e causalidade, - pode orientar o espírito humano na análise do vasto problema da alimentação, como um fenômeno ligado, através influências recíprocas, à ação do homem, do solo, do clima, da vegetação e do horizonte de trabalho (CASTRO, 1937, p. 25-26).
}

Assunto de toda a gente, de todos os dias, de todos os tempos, dá a impressão de coisa sabida, já sem incógnitas, nem lacunas. Infelizmente, está é uma ilusão de quem olha os fenômenos naturais sem se deter para analisar, de quem aborda assuntos fundamentais como diletante, pela superfície, e fica deslizando nessa superfície, sem penetrar no sentido mais profundo, sem auscultar a densidade. Para quem medite um momento sobre a fome, penetrando com fôlego na massa densa e complexa dos fenômenos vivos da nutrição, a fome não constitui assunto de simples referência, mas muito mais sério e complicado, com raízes mergulhadas profundamente no campo da Sociologia, da Filosofia e da Geografia, com influências projetadas longe, nos quadros mais variados de manifestações da vida. E ainda para esses que mergulham na profundeza do fenômeno, não se mostra ele em seu inferior, assunto batido e desvendado, mas problema eriçado de incógnitas, campo de investigações científicas, cheio de sombras e semeado de lacunas (CASTRO, 1937).

\section{A POBREZA NO NORTE PIONEIRO DO ESTADO DO PARANÁ}

Uma das múltiplas possibilidades de compreender o fenômeno da fome é pela pobreza. Por isso, esta parte da pesquisa apresenta os resultados de pobreza no Norte Pioneiro do Estado do Paraná. A formação regional "é explicada pelo processo de formação socioespacial da região, ocorrido no contexto da economia cafeeira" (ENDLICH, 2006, p. 23), que, em determinado contexto histórico-geográfico do Paraná, foi a "mais dinâmica", impulsionando a migração e o empreendimento dessa área. Depois, o declínio da economia cafeeira atuou contraditoriamente à situação inicial, ou seja, expulsando habitantes e influenciando no chamado declínio demográfico, que esvaziou, também, o aspecto funcional, particularmente quanto aos serviços e comércios (ENDLICH, 2006). Assim, inúmeras pessoas se depararam com a ausência ou a insuficiência de emprego e renda, moradia, educação e 
saúde, entre outras necessidades, inclusive a alimentar, gerando pobreza e fome. O Mapa 1 apresenta as taxas de pobreza, em 2010, nos municípios que compõem o Norte Pioneiro do Paraná.

Ele demonstra quatro movimentos de taxa de pobreza que oscilam entre $4,01 \%$ e $28,42 \%$ de taxa de pobreza. Além disso, é possível constatar, de modo geral, que espacialmente a porção Norte do Norte Pioneiro paranaense apresenta taxas menores de pobreza, sendo que os maiores valores dessa porção não superam 12\% da população total dos municípios. Por outro lado, a porção Sul do Norte Pioneiro paranaense revela as maiores taxas de pobreza da região, inclusive com os quatro municípios com valores superiores a 16,01\% da população municipal.

\section{Mapa 1 - Norte Pioneiro do Estado do Paraná. Taxa de pobreza, 2010}

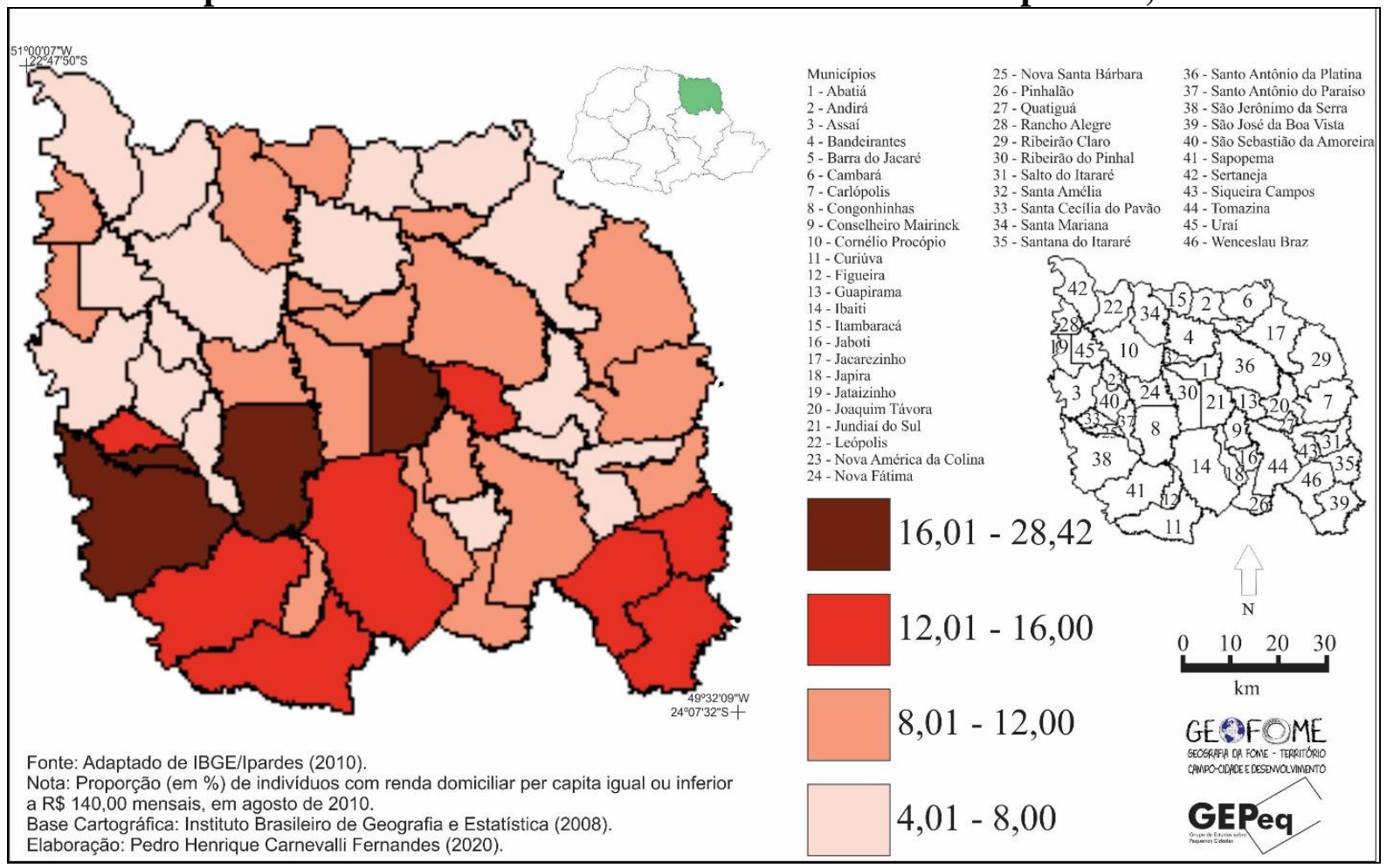

Fonte: Adaptado de Ipardes (2019)

Elaboração: Pedro Henrique Carnevalli Fernandes (2020)

Os menores valores apareceram em Joaquim Távora (4,01\%), Cornélio Procópio $(5,21 \%)$ e Siqueira Campos (5,85\%); 13 municípios ficaram com valores entre $6 \%$ e $8 \%$ : Jacarezinho (6\%), Nova América da Colina (6,25\%), Quatiguá (6,27\%), Andirá (6,27\%), São Sebastião da Amoreira (6,82\%), Santo Antônio do Paraíso (7,32\%), Jaboti (7,39\%), Cambará (7,53\%), Assaí (7,55\%), Leópolis (7,68\%), Bandeirantes (7,73\%), Uraí (7,82\%) e Sertaneja $(7,96 \%)$. 
A Tabela 1 apresenta o ranking de taxa de pobreza, em 2010, dos municípios do Norte Pioneiro do Estado do Paraná, considerando apenas os que tiveram taxas superiores a $10 \%$ da população. Os dados mostraram que 22 municípios (48\% do total) da região possuem mais de $10 \%$ da população absoluta em situação de pobreza. O município de São Jerônimo da Serra, de pouco mais de 11 mil habitantes, tem quase $30 \%$ da população em situação de pobreza, o valor mais elevado da região. Na sequência, Congonhinhas apareceu com 18,82\% de taxa de pobreza; chama a atenção, também, três cidades bem pequenas, com menos de quatro mil habitantes, entre os dez municípios com maiores taxas: Nova Santa Bárbara ( $3^{\circ}$ lugar, com taxa de $17,66 \%$ ), Jundiaí do Sul (4º lugar, com taxa de 16,26\%) e Guapirama ( $9^{\circ}$ lugar, com taxa de $13,15 \%)$.

Tabela 1. Norte Pioneiro do Paraná. Ranking de taxas de pobreza, 2010

\begin{tabular}{c|lrr} 
Posição & Município & $\begin{array}{r}\text { População } \\
\text { absoluta }\end{array}$ & $\begin{array}{r}\text { Taxa de pobreza } \\
\text { (\%) }\end{array}$ \\
\hline 01 & São Jerônimo da Serra & 11.337 & 28,42 \\
02 & Congonhinhas & 8.279 & 18,82 \\
03 & Nova Santa Bárbara & 3.908 & 17,66 \\
04 & Jundiaí do Sul & 3.433 & 16,26 \\
05 & Sapopema & 6.736 & 15,53 \\
06 & Santana do Itararé & 5.249 & 14,80 \\
07 & São José da Boa Vista & 6.511 & 13,38 \\
08 & Wenceslau Braz & 19.298 & 13,24 \\
09 & Guapirama & 3.891 & 13,15 \\
10 & Ibaiti & 28.751 & 12,74 \\
11 & Santa Cecília do Pavão & 3.646 & 12,23 \\
12 & Curiúva & 13.923 & 12,05 \\
13 & Ribeirão do Pinhal & 13.524 & 11,90 \\
14 & Tomazina & 8.791 & 11,90 \\
15 & Jataizinho & 11.875 & 11,45 \\
16 & Itambaracá & 6.759 & 11,31 \\
17 & Santa Amélia & 3.803 & 11,12 \\
18 & Pinhalão & 6.215 & 10,67 \\
19 & Rancho Alegre & 3.955 & 10,53 \\
20 & Salto do Itararé & 5.178 & 10,43 \\
21 & Conselheiro Mairinck & 3.636 & 10,42 \\
22 & Japira & 4.903 & 10,34
\end{tabular}

Fonte: Adaptado de Ipardes (2019)

É importante ressaltar que a taxa de pobreza do Brasil era, em 2010, de $11 \%$ da população total (BRASIL, 2019). Portanto, 17 municípios do Norte Pioneiro do Paraná - 37\% do total - tinham dados piores que a média nacional. No caso do Estado do Paraná, a taxa de 
pobreza, em 2010, era 6\%, ou seja, apenas três municípios da região (Joaquim Távora, Cornélio Procópio e Siqueira Campos) possuíam dados melhores que o da média estadual, enquanto os demais 43 municípios (93\%) apresentaram dados piores que o Paraná.

Na próxima seção, os resultados debatem o alcance do Programa Bolsa Família no Norte Pioneiro do Paraná. Com os dados apresentados, é possível fazer comparações entre os valores de taxa de pobreza e de beneficiados, realçando as localidades que devem ser prioridade no combate à fome na região.

\section{O PROGRAMA bolsa FAMília nO NORTE PIONEIRo do ESTAdo do PARANÁ}

Partindo da existência comprovada da presença da pobreza e, por conseguinte, da fome no Norte Pioneiro do Estado do Paraná, está seção apresenta os resultados quanto ao alcance do Programa Bolsa Família do Governo Federal na região para que se possa refletir acerca da efetividade da política pública frente ao problema elencado.

De acordo com Brasil (2019), o Bolsa Família, criado em outubro de 2003, é um programa que contribui para o combate à pobreza e à desigualdade no Brasil. Esse programa de transferência direta de renda com condicionalidades que beneficia famílias pobres (com renda mensal por pessoa de $\mathrm{R} \$ 89,01$ a $\mathrm{R} \$ 178,00$ ) e extremamente pobres (com renda mensal por pessoal de até $R \$ 89,00$ ) pauta-se na articulação de dimensões essenciais à superação da fome e da pobreza (BRASIL, 2019).

O Bolsa Família, segundo Brasil (2019), ocorre sob três dimensões principais: (i) Complemento da renda: todos os meses, as famílias atendidas recebem um benefício em dinheiro, sendo que esse eixo garante o alívio mais imediato da pobreza; (ii) Acesso a direitos: as famílias devem cumprir alguns compromissos (condicionalidades), que têm como objetivo reforçar o acesso à educação, à saúde e à assistência social, sendo que esse eixo oferece condições para as futuras gerações quebrarem o ciclo da pobreza, graças a melhores oportunidades de inclusão social; (iii) Articulação com outras ações: o programa tem capacidade de integrar e articular várias políticas sociais a fim de estimular o desenvolvimento das famílias, contribuindo para elas superarem a situação de vulnerabilidade e de pobreza. A gestão do Programa Bolsa Família é descentralizada, ou seja, tanto a União, quanto as Unidades da Federação e os municípios têm atribuições em sua execução (BRASIL, 2019).

O valor que a família recebe por mês é a soma de vários tipos de benefícios previstos no Programa Bolsa Família e depende da composição (número de pessoas, idades, presença 
de gestantes etc.) e da renda da família beneficiária (BRASIL, 2019). O valor médio pago no Programa Bolsa Família no Brasil é de R\$189,21 por família e na região Sul do Brasil é de R\$ 169,54 (BRASIL, 2019). Diante desse valor, é inaceitável um discurso contrário do Programa, uma vez que sua existência é essencial no combate à fome e à pobreza.

Segundo Marchesini (2018), 21\% da população brasileira vive com o Bolsa Família. O Estado do Maranhão aparece na liderança de proporção, com $48 \%$ da população do Estado sendo sustentada por beneficiários do programa, seguido por Acre e Piauí, com $43 \%$ cada. A menor proporção está em Santa Catarina, onde 6\% da população do Estado vive com Bolsa Família. No Paraná, 11\% da população estadual é sustentada por beneficiários do Programa Bolsa Família (MARCHESINI, 2018).

No Norte Pioneiro do Estado do Paraná, 12,09\% da população absoluta da região vive com o Programa Bolsa Família, sendo que 11 municípios (24\% do total) apresentaram valores superiores à média regional. Assim, o Mapa 2 apresenta a proporção de beneficiados pelo Programa Bolsa Família nos municípios do Norte Pioneiro do Estado do Paraná, em 2019, sendo possível perceber quatro movimentos, que oscilam entre 3,92\% e 21,09\%. Já a Tabela 2 demonstra o ranking de beneficiados pelo Programa Bolsa Família, em 2019, dos municípios do Norte Pioneiro do Estado do Paraná, considerando apenas os que possuem taxas superiores a $10 \%$ da população absoluta.

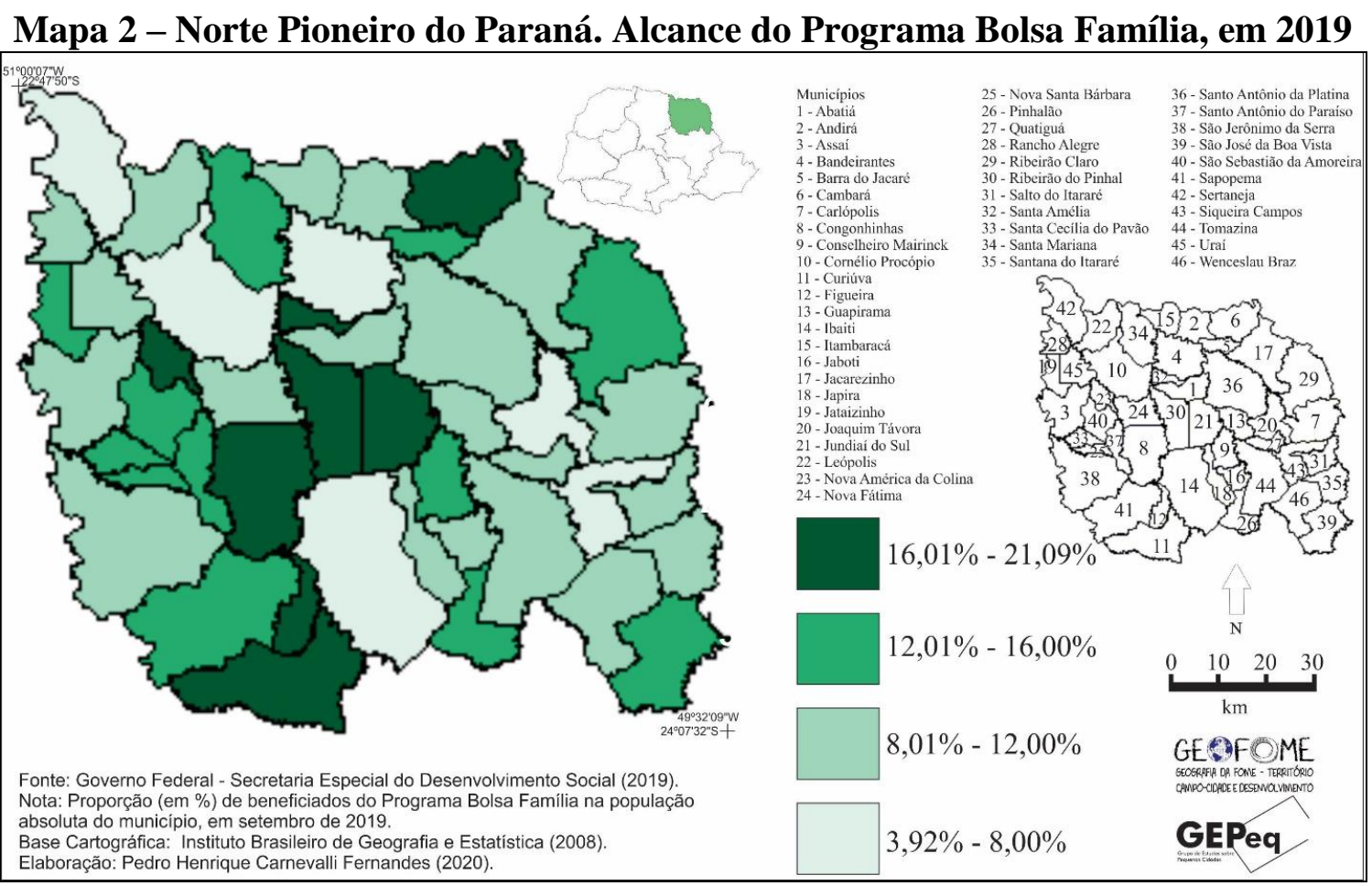

Fonte: Adaptado de Brasil (2019)

Elaboração: Pedro Henrique Carnevalli Fernandes (2020) 
Tabela 2. Norte Pioneiro do Estado do Paraná. Ranking de proporção de beneficiados pelo Programa Bolsa Família, 2019

\begin{tabular}{|c|c|c|c|}
\hline Posição & Município & $\begin{array}{r}\text { População absoluta } \\
(2010)\end{array}$ & $\%(2019)$ \\
\hline 01 & Santa Amélia & 3.803 & 21,09 \\
\hline 02 & Ribeirão do Pinhal & 13.524 & 20,31 \\
\hline 03 & Cambará & 23.886 & 19,15 \\
\hline 04 & Figueira & 8.293 & 19,06 \\
\hline 05 & Nova América da Colina & 3.478 & 17,88 \\
\hline 06 & Curiúva & 13.923 & 17,78 \\
\hline 07 & Congonhinhas & 8.279 & 16,64 \\
\hline 08 & Jundiaí do Sul & 3.433 & 16,05 \\
\hline 09 & Jataizinho & 11.875 & 15,01 \\
\hline 10 & Santa Mariana & 12.435 & 14,80 \\
\hline 11 & Conselheiro Mairinck & 3.636 & 14,60 \\
\hline 12 & Santa Cecília do Pavão & 3.646 & 14,45 \\
\hline 13 & Pinhalão & 6.215 & 14,18 \\
\hline 14 & Sapopema & 6.736 & 13,48 \\
\hline 15 & Santo Antônio do Paraíso & 2.408 & 13,16 \\
\hline 16 & Nova Santa Bárbara & 3.908 & 12,90 \\
\hline 17 & Barra do Jacaré & 2.727 & 12,80 \\
\hline 18 & Ribeirão Claro & 10.678 & 12,56 \\
\hline 19 & São Sebastião da Amoreira & 8.626 & 12,46 \\
\hline 20 & São José da Boa Vista & 6.511 & 12,39 \\
\hline 21 & São Jerônimo da Serra & 11.337 & 11,97 \\
\hline 22 & Jacarezinho & 39.121 & 11,75 \\
\hline 23 & Japira & 4.903 & 11,63 \\
\hline 24 & Jaboti & 4.902 & 11,59 \\
\hline 25 & Quatiguá & 7.045 & 11,28 \\
\hline 26 & Wenceslau Braz & 19.298 & 11,26 \\
\hline 27 & Tomazina & 8.791 & 11,03 \\
\hline 28 & Salto do Itararé & 5.178 & 10,99 \\
\hline 29 & Andirá & 20.610 & 10,93 \\
\hline 30 & Santana do Itararé & 5.249 & 10,65 \\
\hline 31 & Leópolis & 4.145 & 10,62 \\
\hline 32 & Uraí & 11.472 & 10,43 \\
\hline 33 & Itambaracá & 6.759 & 10,25 \\
\hline 34 & Rancho Alegre & 3.955 & 10,09 \\
\hline
\end{tabular}

Fonte: Adaptado de IBGE (2010) e Brasil (2019)

É possível constatar, de modo geral, que espacialmente a porção Centro-Sul do Norte Pioneiro paranaense apresenta as maiores taxas de beneficiados pelo Programa Bolsa Família, inclusive com os oito municípios com valores superiores a $16,01 \%$ da população municipal. $\mathrm{O}$ caso de Cornélio Procópio é atípico: é o município com menor valor $(3,92 \%)$, bem abaixo de 
Joaquim Távora, que aparece na sequência com 6,17\%. Outros três municípios apresentaram proporções menores que 7\%: Siqueira Campos (6,68\%), Sertaneja (6,58\%) e Ibaiti (6,39\%). O município de Bandeirantes ficou com uma proporção de 7,42\% de beneficiados do Programa Bolsa Família e outros seis municípios apresentaram proporção variando entre $8 \%$ e $10 \%$ : Assaí (8,01\%), Nova Fátima (8,16\%), Carlópolis (9,01\%), Guapirama (9,35\%), Abatiá (9,56\%) e Santo Antônio da Platina (9,83\%).

Os dados mostram que 34 municípios (74\% do total) da região possuem mais de $10 \%$ da população absoluta vivendo do Programa Bolsa Família. O município de Santa Amélia, de menos de quatro mil habitantes, tem $21 \%$ da população vivendo do Programa, sendo o valor mais elevado da região. Na sequência, Ribeirão do Pinhal aparece com 20,31\%, Cambará com 19,15\% e Figueira com 19,06\%. Considerando a média do Estado do Paraná, 27 municípios da região (59\% do total), apresentaram valores superiores a essa média paranaense. É relevante comparar os dados de pobreza com de beneficiados com o Programa Bolsa Família para verificar a efetividade das políticas públicas desse programa de combate à fome, à pobreza e às desigualdades na região.

Assim, os resultados demonstraram que 27 municípios (59\% do total da região) apresentaram população vivendo do Programa Bolsa Família superior a população em situação de pobreza. Desses, dez tiveram valores variando entre 0,46\% e 3,00\%: Assaí, Salto do Itararé, Siqueira Campos, Japira, Santo Antônio da Platina, Joaquim Távora, Santa Cecília do Pavão, Ribeirão Claro, Uraí e Leópolis. Efetivamente, chamou a atenção a realidade de cinco municípios que apresentaram uma diferença de mais de $8 \%$ entre a proporção de pessoas em situação de pobreza e de beneficiados do Programa Bolsa Família: Nova América da Colina (11,63\%), Cambará (11,62\%), Santa Amélia (9,97\%), Figueira (9,65\%) e Ribeirão do Pinhal $(8,41 \%)$.

Em contrapartida, 19 municípios (41\% do total da região) apresentaram população vivendo do Programa Bolsa Família inferior a população em situação de pobreza, ou seja, demonstrando que ainda existem pessoas em situação de pobreza que precisam ser contempladas pelo programa. Desses, oito tiveram valores inferiores a 1\%: Carlópolis, Abatiá, Jundiaí do Sul, Bandeirantes, Rancho Alegre, Nova Fátima, Tomazina e São José da Boa Vista. Efetivamente, chamou a atenção a realidade de quatro municípios que apresentaram uma diferença de mais de $4 \%$ entre a proporção de pessoas em situação de pobreza e de beneficiados do Programa Bolsa Família: Santana do Itararé (4,15\%), Nova Santa Bárbara (4,76\%), Ibaiti (6,35\%) e São Jerônimo da Serra (16,45\%). A situação de São 
Jerônimo da Serra é alarmante, ou seja, quase 17\% de pessoas em situação de pobreza não são contemplados pelo Programa Bolsa Família.

\section{CONSIDERAÇÕES FINAIS}

A fome é um fenômeno tão antigo que a sociedade brasileira aprendeu, resignadamente, a conviver com ela, a tratá-la como uma fatalidade - em até certo ponto a banalizá-la, como se fosse um acontecimento natural. No entanto, a fome é um grave problema social ainda contemporâneo, uma negligencia do Estado e da sociedade em geral. Assim, buscou-se, nesta pesquisa, compreender a fome pelo viés conceitual e, depois, verificar a sua materialização na região Norte Pioneiro do Estado do Paraná.

Por anos, a fome foi considerada um tabu, pois como indicou Josué de Castro (1961, p. 49), "quanto ao tabu da fome, havia razões ainda mais fortes do que os preconceitos de ordem moral". As razões mencionadas por ele, têm raízes no escuso mundo dos interesses econômicos, dos interesses de minorias dominantes e privilegiadas, que sempre trabalharam para escamotear o exame do fenômeno da fome.

Logo, houve avanço na academia no debate sobre a fome. No entanto, a contemporaneidade dos estudos teóricos apresentados não se difere, ou seja, poucas alternativas e ações são apresentadas, o que significa que é preciso ampliar e rever a trajetória de desenvolvimento, conhecimento científico e principalmente político.

Quanto ao Norte Pioneiro do Estado do Paraná, os dados mostram que 22 municípios (48\% do total) da região possuem mais de $10 \%$ da população absoluta em situação de pobreza e que o município de São Jerônimo da Serra, de pouco mais de 11 mil habitantes, tem quase $30 \%$ da população em situação de pobreza, o valor mais elevado da região. Apesar desse elevado patamar, os resultados do alcance do Programa Bolsa Família demonstraram uma situação alarmante no município: quase $17 \%$ de pessoas em situação de pobreza não são contemplados pelo programa. Além disso, 17 municípios do Norte Pioneiro do Paraná - 37\% do total - tinham dados piores que a média nacional.

Quanto ao alcance do Programa Bolsa Família no Norte Pioneiro do Estado do Paraná, a realidade de Cornélio Procópio se mostrou atípica no contexto regional: é o município com menor valor $(3,92 \%)$, bem abaixo de Joaquim Távora, que aparece na sequência com $6,17 \%$. Os dados também mostraram que 34 municípios (74\% do total) da região possuem mais de $10 \%$ da população absoluta vivendo do Programa Bolsa Família. O município de Santa Amélia, de menos de quatro mil habitantes, tem $21 \%$ da população vivendo do programa, 
sendo o valor mais elevado da região. Considerando a média do Estado do Paraná, 27 municípios da região (59\% do total), apresentaram valores superiores à média paranaense.

Por fim, ao comparar os dados de pobreza com de beneficiados com o Programa Bolsa Família para verificar a efetividade das políticas públicas desse programa de combate à fome, à pobreza e às desigualdades, os resultados demonstraram que cinco municípios que apresentaram uma diferença de mais de $8 \%$ com mais beneficiados em relação à situação de pobreza e, em contrapartida, quatro municípios apresentaram uma diferença de mais de $4 \%$ entre a proporção de pessoas em situação de pobreza e que não são beneficiados no Programa Bolsa Família.

Estudar a fome, sem dúvida, é percorrer os caminhos da ciência e da técnica no território, mediatizadas pelo mercado (escassez e abundância), e as Geografias da Fome são produtos de apropriação desigual de valor, pois a comida é valor de uso para todos os seres humanos - é a condição da existência humana na Terra.

\section{REFERÊNCIAS}

ABRAMOVAY, Ricardo. O que é fome. São Paulo: Abril Cultural: Brasiliense, 1985.

ADAS, Melhem. A fome: crise ou escândalo? São Paulo: Moderna, 1988.

BRASIL, Secretaria Especial do Desenvolvimento Social. Bolsa Família. 2019. Disponível em: <http://mds.gov.br/assuntos/bolsa-familia> acesso em 03 nov. de 2019.

CAPARRÓS, Martín. A fome. Rio de Janeiro: Bertrand Brasil, 2016.

CASTRO, Josué. Geografia da Fome: o dilema brasileiro: pão e aço. Rio de Janeiro: Civilização brasileira, Ed. 14, 2001.

CASTRO, Josué. O Livro Negro da Fome. $2^{\text {a }}$ ed. São Paulo: Editora Brasiliense, 1966.

CASTRO, Josué. Geopolítica da Fome: Ensaios sobre os problemas de alimentação e de população do mundo. $6^{a}$ ed. v.1. São Paulo: Editora Brasiliense, 1961.

CASTRO, Josué. O problema da alimentação no Brasil. $3^{\circ}$ ed. São Paulo: Edições da Companhia Editora Nacional, 1939.

CASTRO, Josué. A alimentação brasileira à Luz da Geografia Humana. Porto Alegre: Edição da Livraria do Globo, 1937.

ENDLICH, Angela Maria. Pensando os papéis e significados das pequenas cidades do Noroeste do Paraná. 505 p. Tese (doutorado) - Universidade Estadual Paulista, 2006.

FAO. State of Food Insecurity in the World: Measuring different dimensions of food insecurity, 2018. 
FAO. Número de vítimas da fome cai para menos de 800 milhões: a erradicação é o próximo objetivo. Disponível em: http://www.fao.org/news/story/pt/item/288582/icode/2015. Acesso em: 15 out. 2019.

IBGE. Instituto Brasileiro de Geografia e Estatística. Censo 2010. Rio de Janeiro: IBGE, 2010 .

IPARDES, Instituto Paranaense de Desenvolvimento Econômico e Social. Dados dos municípios paranaenses: taxa de pobreza. 2019. Disponível em:

<http://www.ipardes.gov.br/imp/index.php> acesso em 03 nov. de 2019.

LEÃO, Marília. O direito humano à alimentação adequada e o sistema nacional de segurança alimentar e nutricional Brasília: ABRANDH, 2013.

MARCHESINI, Lucas. Beneficiados do Bolsa Família sustentam $21 \%$ da população do país. 05/02/2018. Valor Econômico, 2018. Disponível em:

$<$ https://valor.globo.com/brasil/noticia/2018/02/05/beneficios-do-bolsa-familia-sustentam-21da-populacao-do-pais.ghtml> acesso em: 03 nov. de 2019.

ZIEGLER, Jean. Destruição em massa geopolítica da fome. São Paulo: Cortez, 2013.

Recebido em Abril de 2020

Aceito em Maio de 2020

Publicado em Julho de 2020 